\title{
PENGARUH IKLAN MEDIA SOSIAL INSTAGRAM DAN CELEBRITY ENDORSER ( SELEBGRAM ) TERHADAP MINAT BELI \\ (studi kasus pada toko online shop Keripik pisang coklat Krispbo.id ).
}

\author{
Heny Herawati, \\ Universitas Pendidikan Indonesia \\ henyherawati41@gmail.com
}

\begin{abstract}
ABSTRAK
Tujuan penelitian ini untuk mendapatkan bukti empiris mengenai "Pengaruh Iklan Media Sosial Instagram, dan celebrity endorser terhadap minat beli konsumen (studi kasus pada toko online shop Keripik pisang coklat Krispbo.id ). Pengujian hipotesis menggunakan analisis regresi berganda . Berdasarkan hasil analisis data dan pembahasan, secara parsial variabel Iklan Media Sosial Instagram (X1) berpengaruh positif teradap minat beli (Y). Variabel celebrity endorser (X2) secara parsial berpengaruh positif terhadap minat beli (Y). Secara simultan iklan media sosial instagram dan celebrity endorser berpengaruh signifikan terhadap minat beli. Koefisien determinasi sebesar 65,2\% yang dijelaskan oleh iklan media sosial instagram dan celebrity endorser sedangkan sisanya $34,8 \%$ yang tidak diteliti, seperti harga, kualitas, distribusi dan lain sebagainya.
\end{abstract}

Kata kunci : Iklan media sosial instagram, celebrity endorser, dan minat beli.

\begin{abstract}
The purpose of this study was to obtain empirical "Effect of Instagram Social Media Ads, and celebrity endorser on buying interest online shop consumers (case study on the online shop of Keripik pisang coklat Krispbo.id). Hypothesis testing uses multiple regression analysis. Based on the results of the data analysis and discussion, partially the Social Media Ads variable Instagram (X1) has a positive effect on buying interest (Y). The celebrity endorser (X2) variable partially has a positive effect on buying interest (Y). Simultaneously Instagram social media ads and celebrity endorsers have a significant effect on buying interest. The coefficient of determination of $65.2 \%$ is explained by Instagram social media advertisements and celebrity endorsers while the remaining $34.8 \%$ is not examined, such as price, quality, distribution etc.
\end{abstract}

Key words : Instagram Social Media, celebrity endorser and purchase intention. 


\section{PENDAHULUAN}

\section{Latar Belakang}

Perkembangan teknologi dan komunikasi saat ini yang semakin maju membuat masyarakat Indonesia banyak sekali memanfaatkan kemajuan teknologi tersebut untuk dapat mengembangkan usahanya. Hal ini dilakukan untuk mengembangkan citra merek dan menarik sasaran pada produk yang dimiliki. Pasalnya, dengan perkembangan tehnologi tersebut maka media sosial telah membuat perubahan dalam cara berbelanja masyarakat diIndonesia

Melalui perkembangan komunikasi dan teknologi informasi tersebut telah memudahkan pengguna akses internet untuk menggali informasi yang mereka butuhkan, baik untuk mencari ilmu pengetahuan, dunia usaha, hiburan maupun informasi lainnya. Maraknya pengguna media sosial untuk menggali informasi dibidang usaha yang sangat mempengaruhi teknologi pemasaran yang konvensional menjadi digital diharapkan mampu memberikan manfaat besar dalam dunia bisnis yang kompetitif. Hal ini membuat perusahaan serta pelaku bisnis harus kreatif dan inovatif untuk mengembangkan strategi pemasarannya.

Media sosial adalah sekumpulan aplikasi berbasis Internet yang dibangun di atas dasar Web Teknologi 4.0 yang memungkinkan adanya pembuatan dan pertukaran konten buatan bagi penggunanya. Hal ini memungkinkan kemudahan dalam membangun hubungan satu dengan lainnya yang nantinya akan membentuk suatu jaringan. Media sosial sebagai salah satu bentuk komunikasi melalui media elektonik yang terdiri dari banyak jenis dan kategori diantaranya adalah mesin pencari (Yahoo, Google, Msn, Gigablast, Tanya, dl), sosial jaringan (Facebook, Twitter, LinkedIn, Kaskus, Path, Pinterest, Blog, Tumblr, MySpace, Skype, dll), berbagi foto (Instagram, flickr, foursquare, dll), berbagi video (YouTube, Vine, Instagram, tiktok dll), e-mail (Gmail, Hotmail, Yahoo, dll), perpesanan instan (Ada apa, Garis, BeeTalk, dll), majalah-sharing (Flipboard)

Dari berbagai jenis media komunikasi di atas, hanya sedikit media di Indonesia yang bisa menjadi favorit masyarakat Indonesia . Jejaring media sosial yang menjadi favorit di Indonesia adalah Facebook, WhatsApp, LinkedIn, twitter, namun Instagram dinobatkan sebagai platform media sosial paling efektif untuk 
mendongkrak bisnis (menurut analisis lembaga, Sum All, 2013, maharani 2015, citra 2020). Instagram adalah mobile online layanan berbagi foto, berbagi video, dan jejaring sosial yang memungkinkan penggunanya mengambil gambar dan video, dan membagikannya di berbagai platform jejaring sosial, seperti Facebook, Twitter, Tumblr, dan Flick

Instagram telah melakukan perubahan konten yang diunggah oleh pengguna. Foto-foto yang sebelumnya diposting oleh pengguna sebagian besar merupakan momen-momen pribadi namun kini tersebar luas gambar-gambar produk bisnis untuk mendapatkan pasaran. Faktanya, itu memberikan apa yang disebut celebgram / selebgram (instagram selebriti) di Indonesia. Celebgram / Selebgram juga dikenal sebagai selebriti mendadak. Hal ini dikarenakan kebanyakan dari mereka adalah orang-orang yang jarang muncul di media konvensional, bahkan identitas pemilik akun juga cenderung misterius, namun yang menarik bagi mereka adalah memiliki jumlah followers yang fantastis.

Bagi selebritis yang mendadak ini, mereka memiliki banyak pengikut karena keunikan tampilan konten yang diunggah. Sehingga memicu minat bagi pengguna Instagram lainnya. Namun, selebgramnya adalah juga terdiri dari aktris atau aktor papan atas Indonesia, bintang film, musisi, presenter, dll. Kemudian digunakan oleh banyak merek atau penjual online untuk meminta selebgram menjadi endorser produknya. Selebritis menjadi ikon atau endorser yang dianggap mewakili merek atau produk tertentu untuk menarik calon pelanggan. Ini karena endorser sering menganggap fans sebagai teman, mereka juga terlibat dalam promosi diri. Menjadi figur yang relevan dengan suatu produk dapat mengubah opini publik dan secara tidak langsung meningkatkan minat belinya. Dengan menggunakannya (celebgram / selebgram), para wirausahawan meyakini bahwa ini adalah strategi yang baik untuk meningkatkan pengikut dan secara tidak langsung meningkatkan penjualan

Dalam memasarkan produk atau jasa, perusahaan atau pemilik bisnis harus melakukan iklan. Iklan yang dahulu dapat dilihat melalui media konvensional seperti televisi, radio, koran dan majalah kini sudah menyebar ke dunia media sosial ( internet ). Strategi aplikasi media sosial instagram merupakan salah satu cara bagaimana memberikan informasi bagi pebisnis untuk mengetahui berapa banyak 
reviewers atau akun yang melihat iklan tersebut. Instagram merupakan salah satu media sosial saat ini yang berkembang dan banyak digunakan oleh masyarakat. Instagram merupakan aplikasi photo-sharing, video-sharing untuk menyampaikan pesan dari suatu brand melalui foto/gambar atau video dengan durasi 15 detik.

Berdasarkan data infografis ( gambar 1) menggambarkan saat ini ditahun 2020 kondisi media sosial instagram di Indonesia memiliki pengguna sebanyak 62.00 million, dengan $29 \%$ penggunanya berumur diatas 13 tahun, dengan $49 \%$ penggunanya adalah perempuan dan $51 \%$ adalah laki-laki.

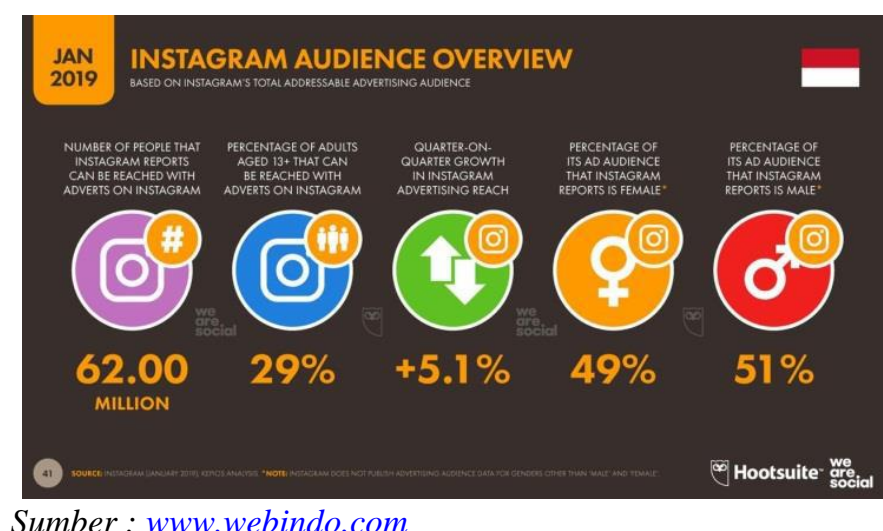

Sumber: $\underline{\text { www.webindo.com }}$

Gambar 1

Instagram Audience Overview periode Januari 2020

Dari gambar 1 diatas terlihat bahwa pengguna dari pada media sosial instagram banyak digunakan oleh masyarakat Indonesia. Dengan demikian penulis tertarik untuk meneliti bagaimana ketertarikan masyarakat terhadap iklan produk yang dilakukan melalui instagram.

Berdasarkan hasil penelitian yang dilakukan pada iklan yang dilakukan oleh akun toko online shop Keripik pisang coklat Krispbo.id di tahun 2019 dan 2020 menujukan bahwa Iklan media sosial instagram yang dilakukan pada Keripik pisang coklat Krispbo.id dalam memperkenalkan produk diketahui hasil rata-rata adalah $23 \%$ pengguna adalah laki-laki , $77 \%$ adalah perempuan, dengan rentang usia 13-25 tahun. Dengan postingan iklan sebanyak 5 kali mendapatkan reviews sebanyak 13218 orang dan total likes sebanyak 359 kali. Maka dengan adanya perbedaan kunjungan dari akun pengguna instagram (viewers) tersebut yang 
mempengaruhi minat beli konsumen dengan ini menjadi sebab peneliti melakukan penelitian.

Tabel 1. Data Pengguna Instagram

Toko Online Shop Keripik pisang coklat Krispbo.id

\begin{tabular}{cccccc}
\hline Iklan Diposting & Laki-Laki & Perempuan & Usia & Views & Like \\
\hline $22 / 08 / 2019$ & $23 \%$ & $77 \%$ & $13-25$ & 3144 & 134 \\
$18 / 12 / 2019$ & $24 \%$ & $76 \%$ & $13-25$ & 2346 & 56 \\
$23 / 01 / 2020$ & $27 \%$ & $73 \%$ & $13-25$ & 1707 & 15 \\
$01 / 03 / 2020$ & $17 \%$ & $83 \%$ & $13-25$ & 4692 & 91 \\
$19 / 07 / 2020$ & $23 \%$ & $77 \%$ & $13-25$ & 1329 & 63 \\
\hline rata -rata & $23 \%$ & $77 \%$ & $13-25$ & & \\
\hline & & \multicolumn{5}{c}{ Total } & 13218 & 359 \\
\hline
\end{tabular}

Sumber : data diolah 2020

Minat beli adalah ketertarikan pembeli atau konsumen terhadap produk sehingga konsumen memiliki niat ingin memiliki dan membeli produk tersebut, ( Kotler dan Keller, 2016). Minat beli konsumen dapat dipengaruhi oleh beberapa faktor diantaranya adalah attention (perhatian), interest (ketertarikan), desire (ingin memiliki), dan conviction (keyakinan), (Lucas and britt, 2012). Media sosial adalah sebagai alat yang dilakukan oleh konsumen untuk membagikan informasi berupa teks, gambar, audio dan video kepada orang lain, (Kotler dan Keller 2016).

Menurut Kertamukti (2015:69) "celebrity endorser adalah individu yang terkenal oleh publik atas prestasinya untuk mendukung produk untuk meraih kepercayaan konsumen dalam minat beli. Celebrity instagram adalah strategi yang sering digunakan oleh perusahaan sebagai alat promosi ( Shimp 2014 ).

Beberapa penelitian sebelumnya menyatakan bahwa terdapat pengaruh positif signifikan dari media sosial instagram terhadap minat beli, (Rachmat, 2016 ) (Deru dan Jovita, 2017), (Sari, 2018 ), Sedangkan penelitian yang dilakukan oleh Handoko, dkk (2019) memberikan hasil bahwa tidak terdapat pengaruh signifikan dari media sosia terhadap minat beli.

Hasil penelitian sebelumnya menunjukkan bahwa terdapat pengaruh positif signifikan dari celebrity endorser terhadap minat beli. (Riska, 2016) ( Mubarak, 2018 ), ( Natalia Junni 2019 ) Sedangkan penelitian yang dilakukan oleh Putri Putri 
dan Patria (2018) hasil dari penelitian ini menunjukkan bahwa tidak terdapat pengaruh signifikan dari Endorsement Selebriti Instagram terhadap minat beli.

Dan latar belakang diatas maka peneliti tertarik untuk mengambil judul penelitian ini adalah : "Pengaruh Iklan Media Sosial Instagram, dan Celebrity Endorser terhadap Minat Beli Konsumen (studi kasus pada toko Online Shop Keripik pisang coklat Krispbo.id).

\section{Perumusan Masalah}

Perumusan masalah pada penelitian ini adalah sebagai berikut :

1. Apakah iklan media sosial Instagram berpengaruh terhadap minat beli konsumen pada toko online shop Keripik pisang coklat Krispbo.id?

2. Apakah Celebrity Endorser berpengaruh terhadap minat beli konsumen pada toko online shop Keripik pisang coklat Krispbo.id?

\section{Tujuan Penelitian}

Berdasarkan rumusan masalah diatas maka tujuan penelitian ini adalah :

1. Mengetahui pengaruh iklan media sosial instagram terhadap minat beli pada toko online shop Keripik pisang coklat Krispbo.id.

2. Mengetahui pengaruh celebrity endorser terhadap minat beli pada toko online shop Keripik pisang coklat Krispbo.id.

\section{Manfaat Penelitian}

Manfaat yang dihasilkan dari penulisan ini sebagai berikut :

\section{Manfaat Teoritis}

Menambah wawasan dan pengetahuan peneliti yang berkaitan dengan bidang pemasaran terutama dalam hal iklan media sosial dan celebrity endorser terhadap minat beli konsumen. Penelitian ini akan sangat berguna dalam mengembangkan teori yang telah diperoleh selama perkuliahan dengan kondisi yang nyata dalam dunia bisnis.

2. Manfaat Praktis 
Penelitian ini diharapkan dapat dijadikan referensi/acuan bagi pengembangan ilmu mengenai pemasaran yang berhubungan dengan upaya peningkatan penjualan dengan memperhatikan faktor iklan media sosial dan celebrity endorser dan berguna untuk penelitian selanjutnya sebagai referensi dalam melakukan kajian terhadap pengaruh iklan media sosial terutama instagram dan celebrity endorser pada penjualan online shop sehingga minat beli dapat menjadi keputusan pembelian.

\section{TINJAUAN PUSTAKA}

\section{Minat Beli}

Minat merupakan kondisi seseorang yang memiliki kecenderungan dan kegairahan yang tinggi serta keinginan yang besar terhadap sesuatu (Muhibbin, 2014).

\section{Iklan Media Sosial Instagram}

Iklan merupakan sarana komunikasi secara tidak langsung dengan dasar informasi mengenai keunggulan atau keuntungan produk dengan menyajian yang menarik sehingga dapat memberikan rasa menyenangkan yang mendasari konsumen untuk melakukan pembelian (Tjiptono 2008:226).

Media sosial adalah sarana kerja sama di antara pengguna yang menghasilkan konten (user generated content) (Mandibergh, 2012).

Instagram adalah sebuah aplikasi berbagi foto yang memungkinkan pengguna mengambil foto, menerapkan filter, dan membaginya ke berbagai layanan jejaring sosial. ( Johansson et al, 2014).

\section{Celebrity Endorser}

Celebrity Endorser adalah salah satu strategi atau konsep terkini yang mampu menyampaikan pesan dari produk serta menganjurkan untuk membeli ( Zohra, 2013) 


\section{Kerangka Pemikiran}

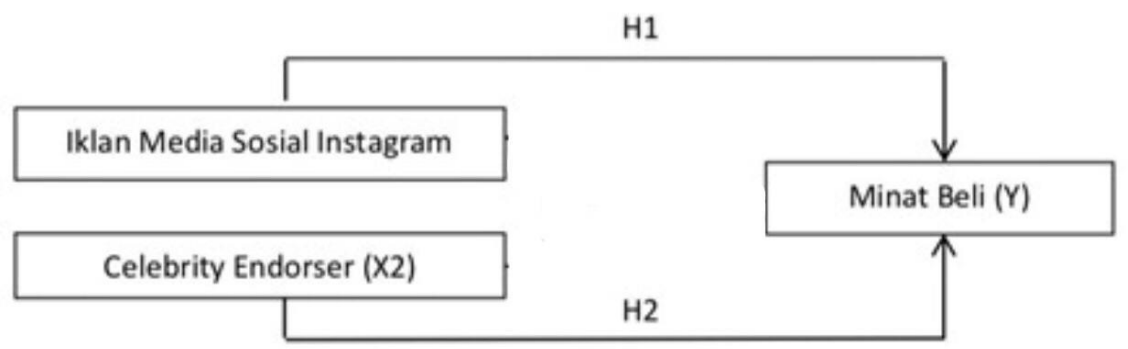

Gambar 2.

Kerangka Penelitian

\section{Hipotesis}

HI : Iklan media sosial Instagram berpengaruh terhadap minat beli konsumen.

H2 : Celebrity Endorser berpengaruh terhadap minat beli konsumen.

\section{METODE PENELITIAN}

\section{Populasi, Sampel dan Sampling}

Populasi dalam penelitian ini adalah pengikut akun media sosial instagram Keripik pisang coklat Krispbo.id pada Juli 2020 sebanyak 1.658 orang. Untuk menentukan sampel maka peneliti menggunakan rumus slovin, Sehingga peneliti telah menentukan jumlah sampel yang akan diambil adalah sebanyak 94 orang pengguna instagram

\section{Jenis dan Sumber Data}

Penelitian ini membutuhkan bukti yang relevan untuk memperoleh datadata maka penulis menggunakan dua teknik pengumpulan data yaitu kuesioner dan wawancara.

\section{Metode Analisis Data}

Untuk menganalisis hubungan antara variabel dependent dan independent, penulis menggunakan uji asumsi klasik sebelum melakukan analisis regresi sederhana dan 
berganda, kemudian analisis korelasi sederhana dan berganda. Analisis dalam penelitian ini menggunakan SPSS ( Stastical Pacage for Social Science) 25. Kemudian melakukan uji kecocokan model regresi melalui koefisien determinasi. Dan terakhir melakukan pengujian Hipotesis yakni Uji T.

\section{HASIL PENELITIAN}

Dalam penelitian ini responden yang digunakan sebagai sampel adalah followers dari akun sosial media instagram Keripik pisang coklat Krispbo.id yaitu 94 responden dengan jenis kelamin laki-laki 37 orang ( $39 \%$ ) dan perempuan 57 orang ( $61 \%$ ). Dengan usia 13-17 tahun 9 orang, usia 18-24 tahun 39 orang, usia 25-34 tahun 35 orang dan diatas 35 tahun sebanyak 11 orang.

\section{Rekapitulasi Tanggapan Responden}

Tanggapan dari 94 responden melalui indikator context penelitian adalah sebagai berikut :

Tabel 2

Rekapitulasi Tanggapan Responden Terhadap Variabel Iklan Media Sosial Instagram

\begin{tabular}{lcc}
\hline \multicolumn{1}{c}{ Indikator } & Indeks & Keterangan \\
\hline Context & 78,9 & Tinggi \\
Communication & 78,1 & Tinggi \\
Collaboration & 78,6 & Tinggi \\
Connection & 80,3 & Tinggi \\
\hline Jumlah & 79,0 & Tinggi \\
\hline Sumber : Data diolah, 2020. & &
\end{tabular}

Tabel 3

$\underline{\text { Rekapitulasi Tanggapan Responden Terhadap Variabel Celebrity Endorser }}$

\begin{tabular}{lcc}
\hline \multicolumn{1}{c}{ Indikator } & Indeks & Keterangan \\
\hline Attractiveness & 78,05 & Tinggi \\
Credibility & 79,7 & Tinggi \\
Expertise & 80,9 & Tinggi \\
\hline Jumlah & 79,55 & Tinggi \\
\hline
\end{tabular}

Sumber : Data diolah, 2020. 
Tabel 4

Rekapitulasi Tanggapan Responden Terhadap Variabel Minat Beli

\begin{tabular}{ccc}
\hline Idikator & Indeks & Keterangan \\
\hline Transaksional & 81,25 & Tinggi \\
Preferensial & 81,00 & Tinggi \\
Eksploratif & 81,13 & Tinggi \\
\hline Jumlah & 81,13 & Tinggi \\
\hline
\end{tabular}

Sumber : Data diolah, 2020.

Berdasarkan tabel diatas, dapat dijelaskan bahwa persepsi responden terhadap variabel Iklan Media Sosial Instagram , Variabel Celebrity Endorser dan Variabel Minat Beli adalah setuju dan memiliki angka indeks yang tinggi diatas 78 ( > 78) dengan demikian artinya bahwa mayoritas responden setuju terhadap context dari iklan media sosial instagram, Celebrity Endorser terhadap Minat Beli Keripik pisang coklat Krispbo.id.

Dari hasil analisis korelasi dapat diketahui bahwa :

1. Iklan media sosial instagram dan minat beli memiliki nilai koefisien korelasi (R) sebesar 0,771 yang menjelaskan iklan media sosial instagram berkorelasi atau memiliki hubungan yang positif dan kuat terhadap minat beli konsumen,

2. celebrity endorser dan minat beli diketahui memiliki nilai koefisien korelasi (R) sebesar 0,771 yang menjelaskan celebrity endorser berkorelasi atau memiliki hubungan yang positif dan kuat terhadap minat beli konsumen

3. Hasil output statistik pada penelitian ini didapat angka 0,652 hal ini menjelaskan bahwa kontribusi yang diberikan variabel iklan media sosial instagram, dan celebrity endorser terhadap minat beli sebesar 65,2\% sedangkan sisanya $34,8 \%$ dipengaruhi oleh faktor-faktor lain yang tidak diteliti.

\section{Pembahasan}

Berdasarkan hasil analisis mengenai hasil penelitian dan interpretasikan sebagai berikut : 


\section{Pengaruh Iklan Media Sosial Instagram terhadap Minat Beli.}

Berdasarkan uji-t menunjukkan bawa variabel iklan media sosial instagram

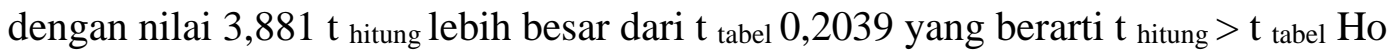
ditolak; Ha diterima, dengan demikian iklan media sosial instagram mempunyai pengaruh yang signifikan terhadap minat beli

Dari hasil uji tersebut sesuai dengan teori bahwa Media sosial merupakan sarana dalam mempromosikan produk, karena media sosial merupakan media pemasaran yang penting dalam menjangkau segmen pasar usia muda dengan cara lebih cepat dan efisien (balakrishnan et.al, 2014). Iklan Media Sosial dapat membangun identitas merek membangun hubungan dengan konsumen, meningkatkan penjualan (Widjojo,2017). Dengan tujuan untuk dapat meningkatkan reaksi konsumen atau calon pembeli terhadap produk yang ditawarkan (Sudaryono, 2016). Media sosial instagram meningkatkan kemampuan dalam komunikasi berupa foto yang dikemas secara kreatif menjadi salah satu faktor yang sangat penting dalam menarik minat atau perhatian konsumen. Aplikasi media sosial Instagram yang mendominasi fitur sharing foto atau gambar ini membuktikan korelasi dalam mempengaruhi minat beli konsumen.

Hasil penelitian ini relevan dengan penelitian yang dilakukan Indika dan Jovita (2017) yang menyatakan bahwa variabel Iklan Media Sosial Instagram berpengaruh positif terhadap Minat beli hal ini dikarenakan iklan media meningkatkan kemampuan dalam komunikasi.

\section{Pengaruh Celebrity Endorser terhadap minat beli.}

Berdasarkan uji-t menunjukkan bawa variabel celebrity endorser 3,899 t hitung lebih besar dari $\mathrm{t}_{\text {tabel }}$ 0,2039 yang berarti $\mathrm{t}_{\text {hitung }}>\mathrm{t}$ tabel Ho ditolak; Ha diterima, maka celebrity endorser mempunyai pengaruh yang signifikan terhadap minat beli. Hasil uji ini sesuai dengan teori yang menyatakan bahwa Celebrity Endorser merupakan staregi yang mampu menyampaikan pesan dari produk serta menganjurkan untuk membeli (Zohra,2013). Celebrity endorser merupakan strategi yang sering digunakan oleh perusahaan sebagai alat promosi (Shimp 2014:462). 
Pada penelitian ini telah ditemukan hasil yang memberikan penafsiran bahwa Celebrity Endorser atau toko pendukung memiliki peranan penting untuk memperkuat strategi pemasaran dalam mempromosikan produk. Hal ini penting karena dapat memberikan kontribusi terhadap penjualan perusahaan bahkan usaha kecil lainnya yang sedang melakukan proses pemasaran. Dalam penelitian ini telah diketahui adanya kemampuan atau pengaruh celebrity endorser terhadap minat beli pada toko online shop Keripik pisang coklat Krispbo.id. Hasil peneiltian ini diperkuat dengan penelitian sebelumnya yang relevan yang dilakukan oleh Nainggolan (2017) menyatakan adanya pengaruh Celebrity Endorser terhadap minat beli dikarenakan adanya kepercayaan, keterampilan, daya tarik, pada tokoh pendukung memiliki kesamaan atau memiliki pengaru positif terhadap minat beli konsumen.

\section{Kesimpulan}

Berdasarkan hasil penelitian dan pembahasan diatas mengenai pengaruh iklan media sosial instagram dan celebrity endorser terhadap minat beli konsumen online shop Keripik pisang coklat Krispbo.id. Dapat dikemukakan beberapa simpulan sebagai berikut :

1. Terdapat pengaruh yang positif dan signifikan antara iklan media sosial instagram terhadap minat beli konsumen. Media sosial instagram meningkatkan kemampuan dalam komunikasi berupa foto yang dikemas secara kreatif menjadi salah satu faktor yang sangat penting dalam menarik minat atau peratian konsumen.

2. terdapat pengaruh yang positif dan signifikan antara celebrity endorser terhadap minat beli konsumen. Celebrity endorser dipercaya dalam menyampaikan iklan, memiliki keterampilan dalam membintangi iklan, memiliki daya tarik, selebriti artis popular yang dikenal dan selebriti yang memiliki kesamaan dengan audience atau konsumen memiliki pengaruh yang positif terhadap minat beli konsumen. 


\section{Saran}

Berdasarkan hasil penelitian dan kesimpulan dapat dikemukakan beberapa saran yang mungkin berguna bagi perusahaan atau pihak lain yang memerlukan yaitu sebagai berikut :

1. Iklan media sosial instagram sangat penting dalam pemasaran suatu produk karena memiliki pengaruh yang signifikan teradap minat beli konsumen, maka diharapkan toko online Keripik pisang coklat Krispbo.id, untuk tetap mempertahankan strategi iklan media sosial pada aplikasi instagram yang telah dilakukan atau dapat lebih meningkatkan penayangan, menambah durasi atau menghadirkan banyak kreatifitas dan inovasi untuk menarik perhatian konsumen pada iklan tersebut sehingga dapat mempengaruhi minat beli konsumen untuk membeli produk dari Keripik pisang coklat Krispbo.id.

2. Celebrity endorser sebagai tokoh pendukung memiliki peranan penting dan berpengaruh signifikan terhadap minat beli konsumen, maka diharapkan toko online shop Keripik pisang coklat Krispbo.id tetap mempertahankan kualitas dari tokoh pendukung tersebut (celebrity endorser) ataupun menambahkan tokoh lainnya yang sedang naik daun atau sedang terkenal di masyarakat agar iklan yang telah dilakukan dapat tersebar dengan luas

3. Bagi peneliti selanjutnya diharapkan dapat melakukan penelitian terhadap variabel-variabel lain yang berpengaruh terhadap minat beli selain variabel iklan media sosial instagram dan celebrity endorser. Diharapkan penelitian selanjutnya dapat melanjutkan penelitian ini sampai keputusan pembelian

\section{Keterbatasan Penelitian}

Dalam melakukan penelitian ini banyak keterbatadan yang ditemui dalam penelitian yaitu :

1. Sampel yang digunakan dalam penelitian ini terbatas yaitu hanya 94 responden.

2. Adanya keterbatasan penelitian dengan menggunakan kuesioner yaitu terkadang jawaban yang diberikan ole responden tidak menunjukkan keadaan sesungguhnya. 
3. Variabel yang mempengaruhi minat beli dalam penelitian ini hanya iklan media sosial instagram dan celebrity endorser, sedangkan masih banyak variabel lain yang mempengaruhi minat beli. 


\section{Referensi}

Abbas, A, dkk. 2018. The Effect of Celebrity Endorsement on Customer Purchase Intention: A Comparative Study. Current Economics and Management Research. 4(1)1-10

Abhishek, \& Sahay, A. 2013. Role of culture in celebrity endorsement: Brand endorsement by celebrities in Indian context. IIMA India Research and Publiations, 1(2), 1-31.

Ahmed, dkk. 2014.Credibility of Celebrity Endorsement and Buying Intentions an Evidence from Students of Islamabad,Pakistan, International Letters of Social and Humanistic Sciences, pp. 1-13,

Andreas, Kaplan M., Haenlein Michael 2010. "Users of the world, unite! The challenges and opportunities of social media". Business Horizons 53 (1). p. 61.

Ash-shiddieq, Fahri N. T.2014. Pengaruh Celebrity Endorser Valentino Rossi terhadap Brand image Sepeda Motor Yamaha: Studi Pada Mahasiswa Fakultas Komunikasi Dan Bisnis, Universitas Telkom Jurnal Universitas Telkom.

Astika, S. T. (2015). Pengaruh Kredibilitas Endorser Selebriti Terhadap Minat Beli Konsumen (Studi Pada Iklan Shampo L'oreal Versi Dian Sastro). Depok: Universitas Indonesia.

Astuti, R. L. M. B., Santoso, H. P., \& Si, M. (2016). Pengaruh Promosi Online dan Celebrity Endorser terhadap Minat Beli Konsumen Tas Online Shop Fani House. Interaksi Online, 17(1), 1-10.

Golzadeh, M J and Shahriari, J E. 2016. Innovation Approach for Examining the Impacts of Organizational Culture on Successfulness of an Organization's Strategy," Current Economics and Management Research, Vol. 2, no. 2, pp. $1-8$.

Kertamukti, R. 2015. Strategi Kreatif Dalam Periklanan: Konsep Pesan, Media, Branding, Anggaran. hal. 69. Jakarta: Rajawali Pers.

Kertamukti.R .2015. Strategi kreatif dalam periklanan : PT Raja Grafindo Persada, Jakarta

Kotler, Philip and Kevin Lane Keller, 2016. Marketing Managemen, 15th Edition, Pearson Education,Inc.

Mubarak, N. M., Fauzi DH, A., \& Nuralam, I. P. (2018). Pengaruh Celebrity Endorser pada Media Sosial Instagram terhadap Keputusan Pembelian 
(Survei Online pada Konsumen Produk Erigo Jakarta melalui Instagram). Jurnal Administrasi Bisnis, 62(1), 18-25

Muhibbin Syah,2014. Psikologi Pendidikan Dengan Pendekatan Baru. edisi 18. PT.Remaja Rosdakarya. Bandung

Prabowo, dkk. 2014. Pengaruh Celebrity Endorser Terhadap Minat Beli (Survei Pada Pengunjung 3Second Store di Jalan Soekarno Hatta Malang), Jurnal Administrasi Bisnis .Vol. 14 : hal. 3

Rachmat, D. O. N., Ariyanti, M., \& Zuliestiana, D. A. (2016). Pengaruh Celebrity Endorser Di Media Sosial Instagram Dalam Promosi Produk Hijab Terhadap Minat Beli Konsumen (studi Kasus Pada Akun Instagram@zahratuljannah Dan@ joyagh).eProceedings of Management, 3(3).

Sari, H. A. (2018). Pengaruh Iklan Media Sosial Instagram Terhadap Respon Konsumen Di Bandar Lampung.

Shimp, Terence A. 2003. Periklanan Promosi: Aspek Tambahan Komunikasi Pemasaran Terpadu. Alih bahasa oleh Revyani Sahrial dan Dyah Anikasari. Edisi Kelima Jilid 1. Jakarta: Erlangga.

Shimp, Terence. A., Andrews, Craig, J. 2013 Advertising, promotion, and other aspects of integrated marketing communication. Ninth edition. USA: Cengage Learning.

Siregar, Syofian. 2013. Metode Penelitian Kuantitatif. Jakarta: PT Fajar Interpratama Mandiri.

Sitti Nurhalimah, dkk 2019 media sosial dan masyarakat pesisir : refleksi pemikiran mahasiswa bidikmisi edisi 1 Deepublish Yogyakarta

Solis, B. 2010. ENGAGE. Wiley John. Canada

Sopiah dan Sangadji, E. Salesmanship (kepenjualan). Bumi Aksara, 2016), hal. 70. Jakarta

Strauss, J. dan Frost, R. 2016. E-Marketing. Edisi 7, Routledge. USA

Sudaryono. 2016. Manajemen Pemasaran Teori Dan Implementasi. Yogyakarta: ANDI.

Sugiyono. 2015. Metode Penelitian Bisnis. Bandung: Alfabeta.

Sulasno dkk, 2020. Literature For Social Impact And Cultural Studies .edisi 2. PT.TRAINDO BANGUN NEGRI. BANTEN 
Shimp, Terence A. 2014. Komunikasi Pemasaran Terpadu Dalam Periklanan Dan Promosi. Jakarta:Salemba Empat.

Tjiptono, Fandy. 2015, "Strategi Pemasaran”, edisi empat, CV. Andi, Yogyakarta Hal 404.

Widjojo, dkk.2017 SARI-SARI PEMASARAN \& APLIKASINYA DIDUNIA BISNIS. edisi 1 .Prasetya Mulya Publishing . Jakarta

Zarella, Dan. 2010. The Social Media Marketing Book. Sebastopol, Canada: O’Reilly Media, Inc. 